\title{
São Tomé das Letras e Lagoa Santa: mineração, turismo e risco ao patrimônio histórico e natural
}

\section{David Ivan Rezende Fleischer}

\begin{abstract}
resumo Sáo Tomé das Letras se mantém através da mineração, da agricultura e do turismo, e Lagoa Santa através de empresas mineradoras, fábricas de cimento e agricultura. A mineração ameaça recursos naturais nas duas localidades, que possuem patrimônios distintos. Esses patrimônios impóem restriçóes, criadas para garantir sua preservação. Diferentes grupos locais buscam alternativas sustentáveis para a conservação deste patrimônio. $\mathrm{O}$ artigo faz uma comparação das duas realidades, procurando entender a sustentabilidade de cada cidade mineira através da análise de atividades específicas como o turismo, a mineração e as iniciativas de preservação de patrimônios culturais. Este artigo baseia-se em dados etnográficos focados em conflitos sociais presentes nos dois cenários e políticas públicas locais guiadas para o desenvolvimento de atividades econômicas sustentáveis para o ambiente e patrimônio locais.
\end{abstract}

palavras-chave Turismo. Meio ambiente. Patrimônio. Cidades mineiras. Políticas públicas.

\section{Histórico}

O estado de Minas Gerais possui diversas cidades que têm como principal atividade econômica a mineração. $\mathrm{O}$ estado possui ricas reservas de minerais metálicos e não-metálicos. A extração é feita por grandes empresas que recebem do Departamento Nacional de Prospecção Mineral (DNPM) autorização de lavra de grandes áreas. Muitos municípios náo possuem plano diretor, por isso, a atividade mineradora segue de forma desordenada, comprometendo nascentes de rios, mananciais e vegetação natural e, em decorrência disso, a qualidade de vida.
O presente artigo faz uma análise de dois municípios distintos: Lagoa Santa e São Tomé das Letras, que possuem forte atividade de mineração. Um está inserido em uma Área de Proteção Ambiental (APA) e o outro faz parte do Circuito Turístico Vale Verde e Quedas D'água, recentemente criado pela Secretaria de Turismo do Estado de Minas Gerais. Os dois municípios apresentam situações diferentes, mas estão diante de um mesmo fenômeno, que é a sustentabilidade de atividades econômicas de alto impacto ambiental.

Ambos os municípios possuem rico patrimônio cultural. Em São Tomé das Letras há um centro histórico tombado pelo Instituto Estadual de Patrimônio Histórico e Artístico de Minas Gerais (IEPHA/MG), que inclui o tombamento da Igreja da Matriz e Igreja do Rosário, vários casaróes antigos, passos coloniais, além de peças de arte sacra; tudo referente ao terceiro período do Barroco Mineiro. Desse período, segundo dados do IEPHA/MG, resta apenas um pequeno acervo, e São Tomé das Letras possui o conjunto mais expressivo. Lagoa Santa possui alguns casaróes antigos além da Igreja Matriz, que foram tombados pelo IEPHA/MG. Lagoa Santa possui como patrimônio mais expressivo o conjunto de sítios arqueológicos.

Lagoa Santa é um município de 36 mil habitantes (IBGE 2000) e faz parte da região metropolitana de Belo Horizonte. A cidade possui uma grande área rural, que vem sendo revertida em área urbana com a criação de vários condomínios privados, além de novos bairros, em parte para acomodar a classe média urbana de Belo Horizonte. 
O município de Lagoa Santa faz parte da APA - Carste de Lagoa Santa, que foi criada em 1990. Sua criação teve o intuito de preservar o grande acervo arqueológico, geológico, espeleológico, paleontológico, biótico e cultural. A APA é amparada por um complexo código de Zoneamento Ambiental, que rege normas de usos do solo, planos de manejo dos recursos naturais, expansão urbana, regras para construção e reforma, além de controle da atividade industrial, que é representada pelas minas de calcário e fábricas de cimento. A APA está localizada em uma zona de transição entre os ecossistemas da zona da mata, cerrado e sertão, com rica biodiversidade. $\mathrm{O}$ patrimônio arqueológico incorporado pela APA e é um dos elementos mais importantes desse zoneamento ambiental. Todos os sítios arqueológicos estão dispostos próximo da superfície em áreas de pastagens, agricultura ou mineração, ficando muito vulneráveis à degradação ou saque. A atividade de mineraçáo apresenta o maior risco para este patrimônio. As mineradoras exploram a calcita e o calcário, muito abundantes na região, desmatam hectares de mata nativa e alteram a dinâmica da natureza destruindo o habitat natural de diferentes espécies da fauna e flora. Boa parte dos bens arqueológicos tombados está dentro de áreas de exploração mineral e estão em constante risco (Souza 1997).

O município de São Tomé das Letras possui aproximadamente 6500 habitantes (IBGE 2000) e está localizado na região sul do estado de Minas Gerais, estando eqüidistante de São Paulo $(240 \mathrm{~km})$ e Belo Horizonte $(250 \mathrm{~km})$. A área urbana do município está localizada no topo de uma montanha a uma altitude de 1480 metros acima do nível do mar, e é rodeada de vales. A vegetaçáo local é de cerrado e conta com grande biodiversidade. O solo no topo da montanha é composto de quartzito, pedra de alta dureza extraída em grandes quantidades e permitindo uma comercializaçáo muito lu- crativa para as pedreiras da cidade. A pedra de São Tomé é uma das características que melhor identifica a cidade. As ruas e calçadas são pavimentadas com pedras. A cidade possui uma arquitetura própria. Boa parte das casas da cidade é construída de pedras extraídas da mineração local. Apesar de várias novas construções de alvenaria, a área urbana ainda é marcada pelas construçóes de pedra e ruas e calçadas de pedra.

A principal economia da cidade ainda é a mineração de pedras de calcário. Outras atividades importantes são também o comércio e a agricultura. $\mathrm{O}$ turismo vem despontando como uma atividade econômica importante para o município, gerando mais empregos e arrecadação. Ainda assim, a mineração continua sendo a grande atividade econômica da cidade e a principal responsável pela consolidação da cidade e por atrair uma grande força de trabalho para o local.

São Tomé das Letras é, desde a década de 1970, um dos principais locais de refúgio para boa parte dos moradores de São Paulo e Belo Horizonte. Muitos estabelecem residência no local depois de visitá-lo como turistas. A cidade possui diferentes atrativos para esses novos residentes. $\mathrm{O}$ meio ambiente ainda é o principal elemento que fez várias dessas pessoas trocarem as duas regióes metropolitanas por esta pequena cidade. $\mathrm{O}$ município possui várias cachoeiras, grutas e mirantes bem preservados e que encantam os visitantes. A vinda desses novos moradores fez com que a cidade incorporasse elementos culturais diferentes, que foram responsáveis pela diversificação de valores e conceitos, transformando a cidade num pólo de atração para místicos e esotéricos.

Lagoa Santa é um município urbanizado, com uma densidade demográfica muito maior que a de São Tomé das Letras. O que atrai novos moradores para Lagoa Santa é a tranqüilidade da regiáo, que ainda tem o ar bucólico de 
cidade de interior, apesar de sua proximidade da cidade grande. No entanto, nos dois municípios, os patrimônios natural e cultural estão sob permanente ameaça pela ação da mineração, agricultura, pecuária e turismo. Este será o ponto de comparação entre as duas realidades.

O patrimônio da APA - Carste de Lagoa Santa foi inventariado pelo IEPHA/MG e Instituto de Patrimônio Histórico e Artístico Nacional (IPHAN). Os bens tombados pelo IEPHA/MG são edificaçóes religiosas como igrejas, santuários e capelas; edificaçóes rurais em fazendas e sítios, complexos de balneário, casarios antigos com arquitetura típica da região; sítios arqueológicos, espeleológicos e paleontológicos que incluem lapas ${ }^{1}$, abrigos, sítios cerâmicos, grutas, sítios com pinturas rupestres e fósseis, e sítios com material lítico ${ }^{2}$. Para o IPHAN, o acervo da APA - Carste de Lagoa Santa inclui outros bens como sítios arqueológicos (mais de 100) e os túmulos do Dr. Lund (arqueólogo dinamarquês que fez pesquisas na região no final do século XVIII) e de seus colaboradores.

A preservação e conservação desses sítios arqueológicos são de responsabilidade das prefeituras dos municípios inseridos na APA e os órgãos competentes. $\mathrm{O}$ zoneamento feito recentemente tratou de dividir a APA em diferentes zonas com distintos usos. Uma zona é destinada à expansão urbana, outra às atividades industriais, outra à expansão agrícola, outra à preservação do patrimônio histórico e outra à preservação das paisagens naturais. A criação desse sistema de zoneamento ambiental leva em

1. O termo "lapa" é utilizado para definir um grande paredão de pedra que se projeta à frente criando um abrigo natural muito utilizado pelas populaçóes préhistóricas. Muitas vezes fica em local elevado e escondido pela vegetação.

2. "Material lítico": termo utilizado pela Arqueologia para designar artefatos e utensílios feitos de pedra, como por exemplo: lanças, machados, lascadores e cortadores. consideração a preservação do patrimônio histórico e artístico presente na APA, bem como no meio ambiente e recursos naturais. Cada zona dispóe de diretrizes apoiadas em diferentes usos. Além dos usos permitidos, cada zona possui usos proibidos, determinados de acordo com as características principais de cada zona. A APA é administrada e controlada por órgãos governamentais como o Instituto Brasileiro de Meio Ambiente e Recursos Hídricos Renováveis (IBAMA), o IPHAN, o IEPHA/MG e a Fundação Estadual de Meio Ambiente de Minas Gerais (FEAM) (MEC/SPHAN 1982).

A valorização da arqueologia no Brasil parte do conceito de patrimônio, que no Brasil tem influência do Movimento Modernista de 1922. Os modernistas defenderam uma valorização da cultura nacional a partir de seus elementos históricos e artísticos regionais. Dessa busca da valorização, veio o estímulo em preservar a história do país através da proteção do seu acervo histórico e artístico. Mário de Andrade foi figura central nessa discussão e um dos personagens principais na criação de um aparato legal e burocrático estatal para a promoção e proteção desse patrimônio (Andrade 1974). A idéia de patrimônio está relacionada ao conceito de tradiçáo, no sentido de uma necessidade de preservar elementos que constituam uma identidade coletiva e contribuam para a construção de memória nacional. A arqueologia no Brasil só pode ser compreendida como patrimônio porque como ciência, como construção de pensamento e produção científica, a arqueologia não possui uma tradição, não está presente nas escolas, dentro das salas de aula e/ou nos livros didáticos. Os bens arqueológicos são patrimônio nacional. Eles são considerados importantes para a compreensão da pré-história brasileira, e por isso devem ser preservados. $\mathrm{O}$ valor dado aos bens arqueológicos está diretamente relacionado com as formas de preservação. 
Uma sociedade só tem interesse em proteger seus bens culturais quando é de interesse coletivo conservar sua memória. A memória nacional tem relação direta com o conceito de patrimônio. Patrimônio são bens que apresentam um valor histórico, artístico, arqueológico e ambiental para uma nação. São bens móveis e imóveis protegidos por lei e preservados e conservados por instituiçóes competentes. Existem, portanto, distintas categorias de "patrimônio": (1) patrimônio histórico, quando se trata de bens históricos como edifícios, espaços públicos, cidades, ligados à história de uma dada sociedade ou país; (2) patrimônio artístico, quando se trata de bens artísticos como pinturas ou esculturas representantes de uma determinada época, estilo artístico de um dado povo; (3) patrimônio arqueológico, quando se trata de bens arqueológicos como artefatos, folclore, arte, local de habitação e meio ambiente de povos extintos, importantes, por exemplo, para a construção de um vínculo entre o passado e presente. Estes três tipos de patrimônio estáo contidos em uma categoria mais ampla, chamada "patrimônio cultural”. Esses bens dotados de valor histórico, artístico ou arqueológico, geralmente, são tombados para que possam ser preservados e passam a fazer parte da memória coletiva de um povo e de sua identidade social (MEC/SPHAN 1980).

Preservar monumentos históricos não é uma preocupação recente no Brasil. No século XVIII, por exemplo, um primeiro caso de preocupaçáo com os monumentos históricos partiu do Conde das Galveias, vice-rei do Estado do Brasil de 1735 a 1749 quando deu ordens ao Governador de Pernambuco para que preservasse as construçôes holandesas dali (MEC/SPHAN 1982: 13). Outros casos sucederam-se até o presente século. Contudo, até então não havia uma lei específica que visasse à proteção do patrimônio.

Outra questão a levar em conta é que a preservação do patrimônio arqueológico está vinculada à preservação do meio ambiente. A
APA - Carste de Lagoa Santa foi criada com esse propósito. Já que os sítios arqueológicos estáo todos ao ar livre, nas matas, cavernas, grutas, florestas, às margens de rios e em paredóes rochosos, é necessário preservar o meio natural em volta para manter os sítios intactos. Assim, a educação ambiental tem papel fundamental para a preservação dos sítios arqueológicos. $\mathrm{O}$ IBAMA de Lagoa Santa produziu cartilhas educacionais, mas não planejou formas eficientes de distribuí-las. O IBAMA de Lagoa Santa possui apenas um funcionário em tempo integral, o que inviabiliza um programa de educação ambiental. As escolas do município de Lagoa Santa criam seus próprios métodos de educação ambiental, como a manutenção de hortas comunitárias e aulas sobre natureza em seu currículo de ciências ${ }^{3}$. Essas iniciativas não fazem referência ao município e seus atrativos naturais e patrimônio arqueológico. Deste modo, não há como conscientizar a populaçáo da necessidade de preservar o patrimônio.

O patrimônio do município de São Tomé das Letras foi inventariado e tombado pelo IEPHA/MG. São considerados patrimônio o Centro Histórico e Matriz de São Tomé das Letras e o Conjunto Arquitetônico e Urbanístico da Capela do Rosário. O objetivo do tombamento é preservar essas edificaçóes que representam o terceiro período do Barroco Mineiro, além do estilo arquitetônico único de São Tomé das Letras, feito todo em pedra.

A responsabilidade pela preservação desse patrimônio é do IEPHA/MG e da prefeitura de Sáo Tomé das Letras. Apesar de ele ter sido tombado ainda na década de 1970, o governo municipal só tomou conhecimento do tombamento em 2000, quando um grupo de recém-eleitos vereadores instaurou na Câmara Municipal uma comissão para a preservação do patrimônio histórico e natural do município.

3. Veja Fleischer 2000: 48-60. 
$\mathrm{O}$ intuito inicial era preservar o ambiente natural da degradação pelo turismo e mineração. Entretanto, ao contatar o IEPHA/MG para verificar a possibilidade de tombar um parque recém-criado, a comissáo descobriu que o município já possuía bens tombados. Atualmente, a Comissão está engajada em defender esse patrimônio histórico, bem como o ambiente natural. $\mathrm{O}$ objetivo é preservar as características do município e com isso atrair mais turistas para a regiáo.

\section{Turismo e mineraçáo como impacto para o patrimônio}

Os municípios de São Tomé das Letras e Lagoa Santa são atualmente parte integrante de rotas turísticas do estado de Minas Gerais. O município de São Tomé das Letras foi incorporado ao Circuito Turístico Vale Verde e Quedas D’Água, que inclui outros oito municípios da regiáo. $\mathrm{O}$ objetivo desse novo circuito turístico é atrair visitantes interessados nos atrativos naturais da região, como cachoeiras, rios, trilhas e grutas e nos esportes que foram introduzidos recentemente, como o rappel, trekking, escala$\mathrm{da}$, mountainbiking e enduro. $\mathrm{O}$ objetivo foi atrair cada vez mais o turista interessado nessas modalidades de esportes e nas belezas naturais. ${ }^{4}$ $\mathrm{Na}$ cidade, os comerciantes vêm investindo em infra-estrutura de restaurantes, pousadas e bares para melhor atender o turista que vem passar o final de semana e descansar. A prefeitura de São Tomé das Letras está muito interessada em investir no turismo porque acredita ser uma

4. A introdução de esportes como atrativo turístico é cada vez mais comum em destinos ecoturísticos. Como a maioria dos visitantes são jovens engajados em atividades esportivas, cidades como São Tomé das Letras vêm investindo em "turismo de aventura", uma modalidade que alia ecoturismo e esportes como uma forma de atrair ainda mais esses visitantes. valiosa fonte de arrecadação para o município. Entretanto, o prefeito atual possui interesses conflitantes por ser dono de uma das maiores mineradoras da cidade. Desse modo, seu apoio ao turismo se dá de forma parcial, respeitando os interesses das mineradoras. A prefeitura está com planos de utilizar o patrimônio histórico tombado como atrativos turísticos, mas ainda não possui infra-estrutura, nem autorização do IEPHA/MG.

Lagoa Santa foi incorporada no Circuito Turístico das Grutas, que inclui outros 11 municípios. Esse roteiro inclui várias grutas onde o turista pode ver as belezas do subsolo brasileiro. Entretanto, poucas grutas possuem infra-estrutura adequada ou plano de manejo. Assim, poucas delas estão abertas para visitação. Visitação de grutas requer autorização prévia do IBAMA e IEPHA/MG ou IPHAN. $\mathrm{Mu}-$ nicípios como Lagoa Santa possuem guias que têm autorização para entrada em alguns pontos que possuem bens arqueológicos. ${ }^{5}$ Lagoa Santa possui também outros atrativos, como um museu de arqueologia e um de aviação ${ }^{6}$, e é rota para o Parque da Serra do Cipó. Esse parque fica no município de Santana do Riacho e está compreendido por outra área de proteção ambiental, a APA - Morro da Pedreira, adjacente à APA - Carste de Lagoa Santa. O Parque da Serra do Cipó atrai muitos visitantes ao longo do ano e o único acesso asfaltado passa por Lagoa Santa. Desse modo, a cidade vira ponto

5. Existem na APA de Lagoa Santa, ao todo, 78 sítios arqueológicos catalogados e registrados no Livro do Tombo do IPHAN. No município de Lagoa Santa, existem 20. Todo esse patrimônio se encontra em propriedade particular. (veja Fleischer 2000: Anexo 1 para lista de sítios)

6. Lagoa Santa é área de treinamento da aeronáutica. $\mathrm{O}$ aeroporto de Confins possui base área para este fim e a cidade de Lagoa Santa possui um setor, o Aeronáutico, que é moradia para oficiais da Aeronáutica, com escola, infra-estrutura para as famílias e o Museu de Aeronáutica. 
de parada para o parque. Esse fluxo tem estimulado estabelecimentos como restaurantes e pousadas na estrada, mas pouco movimento é revertido para a cidade. A prefeitura possui planos de abrir ao público alguns sítios arqueológicos com pinturas rupestres, mas falta um plano de manejo. Existem divergências entre o IBAMA e a prefeitura em torno da visitação a esses sítios. A prefeitura quer construir infra-estrutura para a visitação e o IBAMA exige que o local sofra o mínimo de interferência. $\mathrm{O}$ Zoneamento da APA - Carste de Lagoa Santa estabelece que todas as cavernas, tombadas pelo IPHAN, devem ser mantidas inalteradas e nenhuma infra-estrutura pode ser erguida nas proximidades.

Interesse em desenvolvimento turístico não significa interesse em preservação de patrimônio ou do meio natural. $\mathrm{O}$ uso econômico do patrimônio é geralmente estimulado por desenvolvimento turístico. Turismo cultural é um tipo de turismo que utiliza os atributos históricos e artísticos de um lugar como atrativos turísticos. Museus, edificaçóes históricas e produção cultural compóem esses atrativos. Temse então uma objetificação do outro, do exótico a partir da promoção de uma cultura material local (Stocking 1985). Tanto em Lagoa Santa como em São Tomé das Letras o poder político local não percebeu no patrimônio arqueológico e arquitetônico um potencial econômico de exploração turística.

Atualmente, como observaram Rojek e Urry (1997), turismo e cultura estáo cada vez mais interligados e relacionados. O turista tem interesse em destinos pouco familiares, onde pode vivenciar experiências diferenciadas e conhecer o outro autêntico. A idéia de patrimônio local torna-se parte dessa discussáo por compor a parte material da cultural local. No caso de São Tomé das Letras, é mais fácil a incorporação do patrimônio arquitetônico porque é parte constituinte da história da cidade. $\mathrm{O}$ casario e igrejas barrocas, além de ser parte da história local, também habitam o imaginário nacional, representando uma época importante na constituição da história nacional: ciclo do ouro em Minas Gerais, sistemas políticos e formas de organização social da época.

As duas localidades sofrem o impasse de conciliar o desenvolvimento turístico com a proteção e preservaçáo do patrimônio local. São Tomé vem investindo cada vez mais em turismo. Atualmente, essa é a segunda atividade econômica do município, atrás apenas da mineração. A cidade vem promovendo eventos culturais para promover a imagem do município e atrair cada vez mais visitantes, como ocorre com a Festa de Agosto, quando a cidade recebe 30 mil folióes. Representando 6 vezes a população local, esse número de turistas gera prejuízos ao patrimônio, como, por exemplo, danificação de monumentos em espaço público e vandalismo de edificaçóes. Depois da Festa, eles vão embora sem a menor preocupação sobre o que deixaram para trás. Considerando a arrecadaçáo total da festa, esses prejuízos perdem valor e relevância. Para a prefeitura essa festa é excelente negócio porque engorda a arrecadação anual do município, mas há pouca preocupaçáo com os potenciais danos causados pelo evento. Os prejuízos ao patrimônio não são reparados, apesar da "gorda" arrecadação com a Festa.

Lagoa Santa não promove eventos festivos desse porte como parte de seu calendário turístico. De fato, o turismo ainda é pouco promovido no município, em parte porque os atrativos do município estão além do alcance do visitante. Os sítios arqueológicos não são demarcados e as pinturas rupestres se encontram em paredóes específicos escondidos na mata, ou cavernas de difícil acesso. Todo esse acervo exige orientação de um guia treinado. Em toda a APA, apenas um possui certificação reconhecida pelo IPHAN. Além disso, todo esse acervo 
se encontra em propriedade particular, o que dificulta tanto a fiscalizaçáo quanto o acesso por parte do turista. Poucos visitantes váo ao município atrás desse acervo arqueológico.

Os dois municípios têm problemas com a proteção de seu patrimônio natural e cultural, no entanto a causa em cada um é distinta. Em São Tomé das Letras, o patrimônio é representado pelas edificaçóes barrocas, as esculturas naturais em pedra e as cachoeiras. Nem as esculturas naturais e nem as cachoeiras são tombadas, porém ambos têm um valor simbólico muito importante para os moradores locais. Esses bens colorem o cartão postal da cidade, atraindo turistas. Em Lagoa Santa, o patrimônio sofre com a ausência dos turistas. Seu patrimônio está escondido e afastado. Para que sua proteção ocorra de modo efetivo é necessário que os turistas os commodifiquem, os transformem em objetos de consumo. Isso seria possível se o município estimulasse o turismo histórico com ênfase na visitação de sítios arqueológicos.

Arqueólogos, por outro lado, argumentam que uma maior exposição desses sítios poderia ser sua morte anunciada, uma vez que uma superexposição comprometeria a preservação dos tão sensíveis e vulneráveis bens arqueológicos, além de que uma valorização dos mesmos estimularia o mercado paralelo que age na regiáo há anos, revendendo pequenas peças como pontas de flechas e cacos de cerâmica. É muito interessante a distinção entre o patrimônio arqueológico, o natural e o arquitetônico. Cada um exige uma iniciativa diferenciada de proteção. $\mathrm{O}$ patrimônio arqueológico em Lagoa Santa está no subsolo, na maioria das vezes em propriedade privada. São bens públicos em propriedade privada, o que cria uma tensão entre o poder público e os proprietários. Uma discussão sobre o que é público e o que é privado. A presença do Estado é maior em locais de sítios arqueológicos e os proprietários pre- cisam seguir normas mais rigorosas na gestáo de suas áreas, visando à proteção desse acervo. A proteção do patrimônio público e privado ocorre de modo diferente, às vezes divergente (Canclini 1994). Iniciativas privadas tendem a quantificar a proteção e preservação do patrimônio em termos econômicos. Iniciativas governamentais qualificam o patrimônio em termos de sua importância para a constituição da cultura e história nacionais. Quando se tem a interposição dessas duas esferas, público e privado, a proteção e a promoção do patrimônio tornam-se mais difíceis. No caso de Lagoa Santa, o patrimônio é publico, mas localizado em propriedades particulares. Em São Tomé das Letras, o patrimônio tombado é de propriedade particular. São residências e estabelecimentos comerciais, alem de propriedades da igreja que compóe o patrimônio tombado.

$\mathrm{O}$ patrimônio histórico-arquitetônico em São Tomé das Letras não é uma commodity para os turistas, apesar de estar muito mais visível que os sítios arqueológicos. A vocação ecoturística do município não oferece espaço para a promoção desses bens, simplesmente porque o visitante veio primeiramente para apreciar os atrativos naturais locais. $\mathrm{O}$ patrimônio arquitetônico embeleza a cidade, e para o ecoturista serve apenas para isso.

A falta de um programa de desenvolvimento turístico que valorize esse patrimônio contribui para sua degradação. O visitante está interessado em conhecer lugares novos, experimentar novidades e aproveitar o que o lugar pode lhe oferecer. O patrimônio histórico-arquitetônico de São Tomé das Letras pode ser um dos atrativos que esses visitantes podem vir a usufruir. Os dois municípios se tornaram conhecidos pela propaganda "boca-a-boca". Eram lugares pequenos e desconhecidos que possuíam atrativos. Os primeiros visitantes foram os que fizeram a promoção dos municípios. O que eles costumam promover sáo os atrativos pelos 
quais se interessaram e que experimentaram. Assim, os primeiros visitantes de São Tomé das Letras promoveram as cachoeiras, o estilo de vida alternativo, o misticismo e esoterismo, além das formaçôes rochosas que distinguem o município de seus vizinhos. Os primeiros visitantes de Lagoa Santa promoveram o estilo de vida bucólico, os bons restaurantes à beira da Lagoa e a Serra do Cipó como destino final, depois de uma parada breve em Lagoa Santa para comer, relaxar e seguir viagem.

O turismo é, portanto, gerador de profundas alteraçóes no cotidiano das duas cidades. Novos estabelecimentos comerciais surgem mês a mês para atender ao aumento no número de turistas; o consumo de drogas entre os jovens vem aumentando significativamente; as cachoeiras e trilhas pela mata estáo sendo depredadas por falta de um manejo adequado; e a tranqüilidade do lugar está sendo ameaçada pela falta de respeito dos visitantes.

A construção típica de São Tomé das Letras é feita com lascas de pedra, chamadas pelos pedreiros de folhas, empilhadas uma em cima da outra, fazendo um encaixe perfeito, não deixando nenhuma fresta e dispensando cimento ou argamassa. Por dentro, alguns rebocavam a parede com adobe e pintavam. O chão é de cimento queimado, e o telhado, com madeiramento feito de árvores do cerrado, era coberto com telhas de coxa. Janelas e portas no estilo colonial fechavam o conjunto. Atualmente, poucos casaróes construídos dessa forma ainda estão de pé. A cidade tem perdido parte do aspecto original com a destruiçáo dos casaróes de pedra e construçáo de novos edifícios de alvenaria. A prefeitura não tem uma política de preservação da história local e a população prefere seguir construindo da forma mais fácil e barata. Os defensores das construçóes em pedra não têm respaldo dos outros moradores, que não encontram a mesma praticidade nesse tipo de construção.
Em São Tomé das Letras, os turistas têm comprado boa parte dos imóveis da cidade para transformá-los em pousadas ou casas de veraneio. Eles exercem certa influência na dinâmica da cidade por descaracterizar os espaços urbanos, que está sendo tomado por construçóes modernas e destoantes. $\mathrm{O}$ número de turistas aumenta nos feriados, mas a maioria dos que visitam São Tomé das Letras utiliza a cidade apenas como ponto de apoio para visitar as inúmeras cachoeiras que existem na região. Esse tipo de turista cria problemas como sujeira pelas ruas e cachoeiras, degradação das áreas verdes e vandalismo, entre outros. A prefeitura está investindo em turismo ecológico, que poderá propiciar mais conforto aos usuários que vêm em busca dos atrativos naturais da região, ao mesmo tempo em que trará maior proteção e garantia ao patrimônio natural.

Em Lagoa Santa, as construçóes não têm padráo definido e oferecem outro tipo de ameaça ao patrimônio histórico: no subsolo da maioria dos lotes existe uma quantidade considerável de potes cerâmicos pré-colombianos, de machadinhas semilunares, entre outros artefatos. A prefeitura dá orientação aos proprietários de lotes que contatem o Centro de Arqueologia sobre os achados para que este possa providenciar, junto ao Setor de Arqueologia da Universidade Federal de Minas Gerais (UFMG), a retirada e correta acomodaçáo dos artefatos. A maioria dos moradores não sabe dessa orientação e quando sabem, não avisam porque sabem que o procedimento legal de retirada dos artefatos pode acarretar no embargo de obras de construção civil. Portanto, muitos simplesmente retiram algumas peças que os agrade para usar como decoraçáo em casa e destroem o restante, que é misturado ao entulho removido depois de terminada a obra.

Nos dois municípios a mineração é um potencial foco de conflito entre diferentes atores sociais. Em Lagoa Santa a mineração é a atividade que mais coloca em risco os sítios ar- 
queológicos, além de comprometer recursos naturais, como mananciais e cavernas. A APA - Carste de Lagoa Santa foi criada para proteger os sítios arqueológicos, os sistemas de cavernas que contém pinturas rupestres e parte do ecossistema, dada sua complexidade topográfica e biodiversidade. Assim as mineradoras, com seus métodos de extração agressivos, como o uso de dinamites e operação de maquinário pesado, representam um perigo iminente ao acervo arqueológico que está em sua proximidade. Em São Tomé das Letras, a mineração prejudica o patrimônio arquitetônico porque utiliza também dinamite e transporta a carga em caminhóes pesados que circulam dentro da cidade, além de comprometer cursos d'água por assoreamento de resíduos. O IBAMA, o IEPHA/MG e o governo municipal são os responsáveis pela fiscalização e punição das mineradoras nos dois municípios.

Existe uma diferença entre os dois municípios. No município de Lagoa Santa, as mineradoras são todas empresas de grande porte, algumas multinacionais, com pouca ou nenhuma relação com o município. Todas as atividades são coordenadas por escritórios em Sáo Paulo, e alguns de seus funcionários moram em municípios vizinhos. De acordo com a legislação que rege as áreas de proteção ambiental, é permitida qualquer atividade econômica, desde que se respeite o zoneamento ambiental que delimita áreas específicas para o desenvolvimento de atividades industriais, agrícolas, áreas urbanas e áreas de preservação ambiental. No caso da APA - Carste de Lagoa Santa, as áreas de proteção foram demarcadas de acordo com a localização dos sítios arqueológicos, cavernas, mananciais e cursos d'água. As áreas de atividade industrial foram delimitadas conforme a localização das mineradoras, presentes na região muito antes da criação da APA. Conforme a localização das mineradoras, alguns sítios arqueológicos e espeleológicos ficaram em situação de permanente risco porque, com o zoneamento, permaneceram dentro das propriedades das mineradoras e, conseqüentemente, muito próximas das áreas de mineração. A criação de uma APA náo significa a desapropriação de terra, como acontece com a criaçáo de Parques Nacionais ou Reservas Naturais. Diante deste quadro, os sítios arqueológicos e espeleológicos que permaneceram dentro dessas propriedades após o zoneamento tornaram-se suscetíveis a danos e avarias causados pela atividade de extração mineral.

No caso da APA - Carste de Lagoa Santa, as infraçóes são consideradas mais severas por causa do zoneamento ambiental lá existente e por haver regulamentação específica sobre a condução da atividade mineral. $\mathrm{O}$ município de Lagoa Santa tem obtido sucesso com a aplicaçáo de infraçóes e o recebimento de indenizaçóes por parte das mineradoras, o que não significa uma mudança na atitude das mineradoras. Os danos mais freqüentes são ao acervo de pinturas rupestres presentes em cavernas e grutas próximas às áreas de extração mineral. A região é um rico depósito de calcário e há muito antes da criação da APA as mineradoras já estavam na área extraindo calcário e fabricando cimento. De acordo com dados do IBAMA, FEAM e a Federação das Industrias do Estado de Minas Gerais (FIEMG), o número de autuaçóes às mineradoras não mostrou declínio algum desde a criação da APA, no início dos anos $1990 .^{7}$ Em 2000, o IBAMA e a Prefeitura de Lagoa Santa haviam multado em mais de 1 milhão de reais uma das mineradoras que destruiu por completo um sítio arqueológico, tombado pelo IEPHA/MG. A justiça determinou que o valor serviria como "medida compensatória”. As multas estipuladas pelo IBAMA são elevadas, mas

7. Dados obtidos através de consulta a arquivos na sede da FEAM e da FIEMG, em Belo Horizonte. Dados do IBAMA obtidos através de consulta ao funcionário do IBAMA responsável pela APA Carste de Lagoa Santa. 
não funcionam como mecanismo de coibição da ação destrutiva das mineradoras. Para estas, os sítios arqueológicos são um empecilho para a expansão de sua área de extração. Não existe uma consciência para a preservação desse patrimônio. As mineradoras em Lagoa Santa estão limitadas pelo zoneamento da APA às áreas de extração que tinham antes da criação da APA. Mas a tecnologia permite que a extraçáo seja concentrada e avance em profundidade.

No caso de São Tomé das Letras as mineradoras são menores, se comparadas com as de Lagoa Santa. Todas as mineradoras que atuam no município são de propriedade de empresários locais. A mão de obra é do próprio município ou de municípios vizinhos. As empresas que lá operam extraem quartzito, que é utilizado pela construção civil. A atividade é mais artesanal e possui menos tecnologia investida, porque o custo do produto final é baixo, se comparado com o produto final das mineradoras de Lagoa Santa, o cimento. O estrago é diferente. Com a falta de tecnologia aplicada, as mineradoras locais extraem pedras somente próximo à superfície. Assim, as jazidas avançam horizontalmente, ocupando cada vez mais área de mata nativa. A extração de quartzito foca em um formato específico de pedra: as lascas ou folhas, que têm como destino final a construção civil. Além das folhas, existe um outro formato, que é a rocha. Por um processo geológico diferenciado, esta possui dureza muito superior e não tem boa aceitação no mercado. Segundo os operários das mineradoras, o aproveitamento na extraçáo náo passa de $40 \%$. Todo o resto vira dejeto e deve ser acomodado em montanhas de pedra com altura máxima de cinco metros. Essas montanhas modificam a topografia da cidade pois fazem surgir no horizonte montanhas quadradas e sem cobertura vegetal.

Outro fator que agrava a degradação do meio ambiente em São Tomé das Letras é o fato de o município não estar inserido em uma
APA, portanto náo possui plano de manejo ou zoneamento ambiental. Frente a este quadro, a atividade das mineradoras no município é muito mais agressiva: a extração causa maior impacto ambiental e náo existe limite para a expansão da mineração. Até recentemente, a atividade de mineração estava avançando em direção à área urbana do município, estando a poucos metros de algumas casas. Foi preciso criar uma regulamentação para o uso de dinamite e para a distância segura das casas. Previamente a essa regulamentação, as mineradoras dinamitavam os bancos de pedra várias horas durante o dia, abalando as estruturas das casas e edificações históricas.

Uma análise sociológica dos conflitos sociais nos mostra que o meio ambiente é compreendido de forma diferente em cada município. $\mathrm{O}$ conflito em São Tomé das Letras ocorre entre ecoturismo e mineração, em Lagoa Santa, entre mineração e APA. A mineração e seu potencial de degradação ambiental está no centro da discussão. O motivo de discussão em São Tomé é de que a atividade de mineração está em direta oposição à atividade de conservação ambiental promovida pelo ecoturismo. Mineração e ecoturismo são atividades econômicas, que seguem lógica de mercado. Entretanto, mineração é uma atividade econômica extrativista, enquanto ecoturismo é uma atividade econômica com intenção de conservação. As duas consomem os recursos naturais locais, só que de modo distinto. Para o setor de ecoturismo, que envolve empresários locais e de outros centros urbanos do setor de hospedagem, comércio e lazer, a mineração representa um risco à sustentabilidade dessa atividade. $\mathrm{O}$ assoreamento de rios e a devastação de áreas de mata nativa desconstroem a imagem de cidade ecoturística e invalidam a promoção do município como lugar de natureza exuberante e bem preservada, como o fazem os guias de turismo produzidos pelos empresários locais. 
Nessa discussão, centrada no patrimônio natural, não está presente a situação do patrimônio histórico, talvez porque o patrimônio natural seja mais importante para o desenvolvimento ecoturístico. Como o setor de ecoturismo concentra suas preocupaçóes na qualidade do meio natural, sobra pouca preocupação com o patrimônio histórico. Assim, desqualifica-se esse patrimônio em detrimento do patrimônio natural. A prefeitura não tem uma política clara de preservação do patrimônio local, apesar de existir um tombamento realizado pelo IPHAN, na década de 1970, da Igreja Matriz, da Praça da Matriz e do casario que circunda a praça, a Igreja do Rosário e alguns Passos. ${ }^{8} \mathrm{~A}$ preservação do patrimônio é um tema polêmico, que tem gerado algumas brigas dentro da prefeitura e entre os moradores.

Os moradores mais recentes em São Tomé das Letras, preocupados com a preservação dos recursos naturais, com a manutenção da paisagem e dos edifícios históricos, iniciaram o conflito com as mineradoras, fazendo denúncias constantes à prefeitura municipal, ao IBAMA e a FEAM. Na época, final da década de 1980, o entáo prefeito se sensibilizou com a preocupaçáo dos moradores e pediu uma intervenção do IBAMA no local. O órgão federal impôs uma série de normas para regulamentar a atividade mineradora no município. Dentre as mais significativas estão a determinação de uma distância mínima da área urbana, a criação de horários fixos para o uso de dinamites e a regulamentação para a disposição de dejetos da mineração. Com a imposição de normas

8. Os passos são pequenas capelas de $3 \mathrm{~m}^{2}$ que eram utilizados na procissão da Via Sacra. Cada Passo marcava um dos passos da procissão (muito comum em cidades mineiras). Em cada um, os religiosos paravam para rezar. Mas a má conservação dos passos fez com que vários fossem demolidos e outros fossem abandonados, restando apenas 6 dos 12 originais. Atualmente, a conservação é feita pelos próprios moradores, que cuidam do passo mais próximo de sua casa. restritivas, as mineradoras tiveram que desativar áreas de mineração que se encontravam dentro do espaço urbano; reduziram o ritmo de extração porque só podiam dinamitar os bancos de pedra duas vezes ao dia (antes dinamitavam até 10 vezes); e tiveram seus custos elevados para disporem corretamente os dejetos. O atual prefeito (2000-2008) de Sáo Tomé das Letras é dono da maior mineradora do município e tem sido omisso diante de atos ilícitos praticados por mineradores. Esta situação não é positiva para a preservação ambiental e do patrimônio no município. A Câmara Municipal criou uma comissáo para promover a preservação do patrimônio histórico, artístico e natural da cidade, mas tem encontrado dificuldades para implementar algumas de suas iniciativas porque o prefeito freqüentemente veta os projetos de lei apresentados pela Câmara.

A discussão em Lagoa Santa é outra. A mineração representa um risco à sustentabilidade do patrimônio arqueológico. A cidade não tem atividade de ecoturismo. A discussão, portanto, se concentra no fato de a mineraçáo estar em direta oposição aos mecanismos de proteção do patrimônio arqueológico, justamente porque os sítios arqueológicos estão muito próximos das áreas de extração mineral. $\mathrm{O}$ embate ocorre entre as empresas de mineração e o conselho diretor da APA, composto pelo IBAMA, Conselho Municipal de Meio Ambiente (CODEMA), Setor de Arqueologia da UFMG e Prefeitura de Lagoa Santa'. Assim, o conflito mantém-se no nível técnico e freqüentemente focalizado nos problemas de gestáo da APA. Ao contrário de São Tomé das Letras, o patrimônio histórico, cultural e natural são considerados de forma conjunta. A proteção do patrimônio

9. São quatro os municípios que compóem a APA Carste de Lagoa Santa: Lagoa Santa, Vespasiano, Pedro Leopoldo e Matozinhos. Mas a SEDE do IBAMA na APA está dentro do município de Lagoa Santa, e é este que participa das decisóes do conselho diretor. 
arqueológico depende da proteção do meio à sua volta.

Como Lagoa Santa está inserida em uma APA, a presença do IBAMA é constante. A prefeitura da cidade também está sempre presente, por ser encarregada de preservar o patrimônio arqueológico através de seu Centro de Arqueologia. São Tomé das Letras, por outro lado, não é beneficiada pelo poder itinerante do IBAMA. Como não possui áreas protegidas, a fiscalização das mineradoras só ocorre quando existe uma denúncia formal ao IBAMA. Quando não é o caso, cabe à prefeitura fiscalizar, mas, como o prefeito é dono de uma mineradora, isso náo costuma ocorrer.

O patrimônio arqueológico cria um campo relacional, onde os grupos sociais envolvidos interagem. A valorização dada à Arqueologia é diferente para cada grupo. Os grupos sociais possuem interesses divergentes, criando uma situação de conflito que não é de simples resolução. $\mathrm{O}$ conflito citado acima entre empresas de mineração e o conselho diretor da APA - Carste de Lagoa Santa pode ser melhor compreendido se observado mais detalhadamente. Os vários atores sociais presentes na APA possuem conflitos menores entre si: existem conflitos individualizados entre IBAMA e mineradoras, prefeitura e IBAMA, prefeitura e mineradoras, IBAMA e população local, IBAMA e vândalos, arqueólogos e prefeitura, arqueólogos e IBAMA, arqueólogos e população local, e arqueólogos e vândalos.

$\mathrm{O}$ conflito entre as mineradoras e o IBAMA recai sobre as infraçóes que as primeiras cometem tanto ao código ambiental brasileiro, quanto às leis específicas que regem a APA. Como o IBAMA é o órgão responsável pela proteção dos sítios arqueológicos, qualquer degradação por parte das mineradoras a esses sítios envolverá o IBAMA. As leis ambientais estabelecem normas para a atuação das mineradoras. Elas devem seguir estas normas para poderem operar dentro da APA. Quem aplica as normas é o IBAMA. As mineradoras não desejam interromper sua atividade. Querem explorar cada vez mais, de forma contínua. A FIEMG é o órgão que geralmente negocia com o IBAMA. É um órgão privado, parte integrante da Confederação Nacional das Indústrias (CNI) e responsável por dar amparo legal e apoio tecnológico às indústrias do estado de Minas Gerais. Ela defende os interesses das mineradoras tentando negociar uma decisão conciliatória com o IBAMA.

O conflito entre a prefeitura e o IBAMA acontece quando a primeira comete infraçóes contra o patrimônio natural. Geralmente isso ocorre quando a prefeitura pretende realizar obras de infra-estrutura, tanto em área urbana quanto rural, dentro da APA. Qualquer obra deve ter previamente um Estudo de Impacto Ambiental (EIA) aprovado pelo IBAMA e depois um Relatório de Impacto Ambiental (RIMA) que vai anexado ao processo de liberação da obra. Esse estudo deve incluir um laudo do Centro de Arqueologia da UFMG para possíveis impactos ao patrimônio arqueológico, e também um programa de manejo que pode incluir a retirada prévia de artefatos, caso sejam encontrados. Todos os projetos devem passar por esse processo burocrático, e às vezes as prefeituras simplesmente pulam essas etapas do processo e partem para a execução. O IBAMA, com apenas um funcionário na APA - Carste de Lagoa Santa, não tem capacidade de fiscalizar de forma eficiente todas as infraçóes que ocorrem dentro da APA.

A prefeitura de Lagoa Santa possui conflitos com as mineradoras, mas geralmente perfila ao lado do IBAMA. Quando o problema é relacionado às mineradoras, o IBAMA e prefeitura ficam lado a lado na briga enquanto, em casos como de obras públicas, duelam entre si. A mineradora que comete infraçóes ambientais tem que resolver o problema na justiça. Isso 
geralmente resulta em medidas compensatórias pagas ao IBAMA e à prefeitura, mas que nem sempre resolvem o problema da degradação ao patrimônio arqueológico. Muitas vezes o IBAMA e a prefeitura entram em acordo para aplicar o valor monetário da medida em outras atividades que não são relacionadas diretamente à proteção do patrimônio arqueológico. Os mecanismos de proteção ao patrimônio arqueológico são tão precários que qualquer destruição por parte das empresas de mineração é irreversível. Não há como recompor pinturas rupestres de uma caverna ou gruta que viraram entulho.

A população tem atrito com o IBAMA, resultado da função fiscalizadora do órgão. De acordo com o diretor da sede do IBAMA na APA - Carste de Lagoa Santa, "a populaçáo acha que o IBAMA é polícia. Polícia Ambiental"10. O mesmo ocorre com o CODEMA. Este órgão é mais atuante, possui mais agentes e aparece mais. Às vezes os agentes são rechaçados pela populaçáo, que desconhece leis ambientais e formas de conduta sob a legislação que rege a APA - Carste de Lagoa Santa. O vandalismo é o ato mais agressivo e é freqüentemente cometido contra as pinturas rupestres. O IBAMA não tem como fiscalizar todos os pontos. São mais de dez paredóes com pinturas rupestres espalhados por toda a área da APA - Carste de Lagoa Santa e constituem parte expressiva dos bens tombados pelo IPHAN.

Os arqueólogos possuem conflitos mais tênues com alguns desses atores sociais. Em entrevistas com alguns deles que trabalham na UFMG, foi possível observar que discordam de ações da prefeitura, IBAMA, IPHAN, IEPHA/ MG e população local. Entre a prefeitura e os arqueólogos, o objeto do conflito é o descaso da prefeitura com o patrimônio arqueológico. Isto pode ser observado tanto pela falta de pre-

10. Parte de entrevista concedida pelo presidente da sede do IBAMA na APA Carste de Lagoa Santa em março de 2000. Veja Fleischer 2000: 40 para maiores detalhes. servação e conservação do patrimônio arqueológico quanto na ausência de políticas públicas que incluem a educação da população. Quanto ao IBAMA, os arqueólogos acreditam que ele deva se unir à prefeitura na elaboração de projetos de educação ambiental junto à população que compreendam também a arqueologia. Em relação à população local, os arqueólogos acham que é ela a responsável pela pilhagem dos sítios e vandalismo dos paredóes, mas acreditam que a razão disso seja falta de conscientização, e que isso pode ser resolvido com a ajuda da prefeitura e do IBAMA. As mineradoras e os exploradores e depredadores são rechaçados pelos arqueólogos por apresentarem uma ameaça ao patrimônio arqueológico. Estes acadêmicos têm uma briga declarada contra esses atores que exploram, danificam ou destroem vários sítios, inclusive levando muitas peças ou lascas de pedra embora.

Desta forma, os conflitos em torno da arqueologia variam conforme os atores sociais envolvidos, de acordo com a questão específica da arqueologia e das afinidades entre os diferentes grupos (Simmel 1955). Analisando a situação através da dicotomia público-privada, pode-se compreender melhor como é dada a valorização do patrimônio histórico pelos diferentes atores sociais envolvidos. Esse patrimônio está, em sua maioria, dentro de áreas particulares, e seus donos têm obrigação de preservá-lo. De acordo com o Decreto-Lei número 25, de 30 de novembro de 1937, todos os bens móveis e imóveis, tombados como patrimônio histórico e artístico, são de propriedade do Estado (Governo Federal ou Estadual) e, estando em propriedade particular, cabe ao proprietário zelar pela integridade deste patrimônio, seja ele um bem artístico, histórico, arqueológico, espeleológico, arquitetônico, paisagístico ou natural. Cabe também ao Estado auxiliar na proteção desse patrimônio, impedindo sua destruição, dilapidação, mutilação ou alteração. 
Enquanto em Lagoa Santa a prefeitura tem um comprometimento maior com a preservação do patrimônio local, em Sáo Tomé das Letras a prefeitura cria impedimentos para o mesmo. Comum entre as duas cidades é a degradação ambiental causada pela mineração. Enquanto numa a mineraçáo abala (e às vezes destrói) sítios arqueológicos e espeleológicos, na outra os mananciais são contaminados e as estruturas de edifícios tombados no centro histórico ficam abaladas. Ainda não existe no Brasil um aporte legal para orientar a atividade de ecoturismo. Afora isto, as discussôes sobre desenvolvimento de ecoturismo não costumam combinar meio ambiente com desenvolvimento. Como afirma Butler (2000), as questóes de meio ambiente são tidas como algo automático em desenvolvimento de ecoturismo, sem que se discuta sua utilização, os impactos e as formas de gestáo. A utilizaçáo do meio ambiente mudou muito nos últimos anos e sua degradação está em ritmo cada vez mais acelerado. Assim, políticas públicas para o ecoturismo deveriam incluir mecanismos de gestáo conciliada entre meio ambiente e ecoturismo.

São Tomé das Letras é uma cidade dividida. Os grupos de ecoturismo e de mineração são representados por nativos e forasteiros, respectivamente. ${ }^{11}$ Há momentos de concórdia ou discórdia diretamente imbricados com as relaçóes de conflito e as redes de afiliação de grupos (Simmel 1955). Segundo Simmel, o objetivo de um conflito é resolver divergentes dualismos (no caso de conflitos envolvendo turistas, forasteiros e nativos) para se atingir um consenso de

11. Os termos "nativos" e "forasteiros" foram adaptados dos termos "established" e "outsiders" respectivamente, utilizados por Elias (2000). A relação entre nativos e forasteiros se dá de forma muito semelhante ao analisado por Elias. Os conflitos e as identidades de grupo também respeitam essa diferenciação, que é baseada em local de origem, identidade funcional, crença religiosa e posicionamento político. grupo. $\mathrm{O}$ espaço urbano é um típico lugar para se encontrar relaçóes de conflito por concentrar em um espaço reduzido um grupo de pessoas com diferenças de valores, biografias, trajetórias, expectativas, visóes de mundo, enfim, "The whole inner organization of urban interaction is based on an extremely complex hierarchy of sympathies, indifferences, and aversions of both the most short-lived and the most enduring kind." 12 (Simmel 1955: 20)

Deste modo, o espaço urbano se apresenta como campo de possibilidades para o conflito, porque o indivíduo se relaciona com diversos outros num espaço limitado. Simmel aponta que as pessoas que vivem em cidades estão em contato diário com diversos estímulos que saturam e criam "antipatias" ou impedimentos a relacionamentos mais intensos. Os conflitos se intensificam em cidades pequenas porque o campo de possibilidades de distanciamento é reduzido e as interações mais intensas. É em São Tomé das Letras que isso se torna mais evidente. O espaço urbano, no ano de 2000, possuía apenas 4 mil habitantes. Todos esses habitantes se conhecem e sabem a que grupo pertencem. $\mathrm{O}$ conflito em torno da atividade de mineração é constante e o ecoturismo rapidamente expandindo-se no município aumenta a animosidade entre os grupos. As características de identificação de cada grupo social são expressas pela sua preferência política, econômica, social e cultural.

Como na maioria das cidades de Minas Gerais que têm atividade de extraçáo mineral, a preservaçáo do patrimônio histórico, arqueológico, artístico, cultural, natural e paisagístico fica em segundo plano diante do desenvolvimento econômico da regiáo proporcionado

12. “Toda a organização interna de interaçóes urbanas é baseada em um complexo sistema hierárquico de simpatias, indiferenças e aversóes tanto das mais simples como das mais difíceis de se resolver" (Tradução do Autor) 
pela mineraçáo. A prefeitura de Sáo Tomé das Letras ignora a destruição ambiental e patrimonial da cidade.

A Câmara Municipal de São Tomé das Letras criou recentemente um grupo de trabalho que tinha por objetivo averiguar o estado de conservação do patrimônio local e possivelmente propor alternativas para sua preservação. A iniciativa pretendia verificar a possibilidade de constituir um Parque Ecológico e integrá-lo como atrativo ecoturístico, que teria como objetivo principal limitar o avanço da mineração em direção ao espaço urbano e também o avanço da cidade em direção à área natural. Com o rápido desenvolvimento do ecoturismo no município, novas casas ${ }^{13}$ estão sendo construídas, cada vez mais próximas das áreas de mata nativa, contribuindo para a destruição da originalidade da cidade. Os vereadores estáo em confronto direto com o prefeito e contam com o apoio do setor de ecoturismo que demonstra preocupaçóes com a proteçáo ao patrimônio natural. A parte da população que trabalha nas mineradoras é a que teme as novas restriçóes, porque elas podem representar no futuro próximo o fim dos seus empregos.

Todo o engajamento em torno da criaçáo de um parque ecológico decorre da preocupação em proteger o patrimônio natural. $\mathrm{O}$ patrimônio arquitetônico da cidade está ameaçado e o turismo pode ser um fator catalisador de uma mudança na política local. A grande maioria dos turistas visita São Tomé das Letras atraída por sua paisagem pitoresca. Como dito antes, o maior interesse dos turistas está nas belezas naturais do município, porém uma recente mudança no perfil do visitante vem aos poucos mudando a forma como se percebe o patrimônio histórico-arquitetônico. Até 2001, o acesso a cidade era feito por estrada de terra que, du-

13. As novas casas são de turistas que vêm para finais de semana, de moradores locais, que mudaram da zona rural, ou de pessoas que trabalham no comércio. rante a época das chuvas, só permitia a passagem de caminhôes ou veículos de tração nas quatro rodas. Isso limitava muito a vinda de turistas. $\mathrm{O}$ perfil dos visitantes era o de pessoas jovens (entre 16 e 23 anos), aventureiras, que viriam a qualquer custo. Com o asfaltamento, o perfil do turista se diversificou e a cidade passou a receber turistas mais velhos (entre 27 e 60 anos) interessados em aproveitar os bons restaurantes e bares e apreciar a arquitetura em pedra e as construçóes do período Barroco. As casas de pedra encantam e dáo um certo ar de bucolismo, como se lá estivesse parado no tempo. Esse patrimônio arquitetônico ainda é a primeira foto que o visitante vê nos guias turísticos da cidade.

Com a intensificaçáo do turismo ocorre um aumento no fluxo de informaçóes, bens e serviços em São Tomé das Letras que vão sendo incorporados ao ethos da cidade (Appadurai 1996). Por exemplo, a prestação de serviços se diversificou oferecendo maior amplitude de opçóes de hospedagem, alimentação e lazer. Hoje, encontra-se em São Tomé das Letras restaurantes de comida japonesa, creperias, pizzarias, cafés e churrascarias; pousadas com piscina aquecida e café da manhã completo; passeios turísticos em vans e jipes, atividades de lazer como shows de rock no meio das pedras, competiçóes de enduro e mountainbiking, passeios ciclísticos e vários pontos para prática de esportes radicais. Algumas destas novidades podem parecer comuns por serem encontradas em várias outras cidades, mas quando foram introduzidas em São Tomé das Letras, causaram um impacto na vida local. Os moradores locais assimilam com muita facilidade as novidades trazidas pelos turistas. A assimilaçáo desses fluxos, segundo Appadurai (1996), representa a participação do município em uma estrutura de poder maior, a nível global. Turismo em geral é uma atividade globalizante, onde interesses locais são subordinados a interesses federais 
e internacionais. Partindo dessa perspectiva, a preservação do patrimônio, o desenvolvimento de ecoturismo e a atividade de mineração devem ser compreendidos como partes desse campo relacional das lógicas de mercado. Ecoturismo e mineração estão em consonância com interesses de mercado que visam a exploração de recursos locais, seja pelo modo extrativista ou pelo modo conservacionista. A preservaçáo do patrimônio representa o interesse de manter estático um período da história, para que seja consumido como mercadoria por turistas.

O turismo é uma importante fonte geradora de renda e de desenvolvimento para o município. O governo do estado de Minas Gerais tem incentivado os municípios com potencial turístico a traçarem um plano de exploração turística e desenvolverem programas que promovam o turismo sustentável. Para isto o governo estadual mapeou o estado, classificando regióes com potencial turístico. São Tomé das Letras passou entáo a constar nos roteiros turísticos do estado de Minas Gerais e da EMBRATUR e passou a receber visitantes de várias partes do mundo durante feriados prolongados como o do Carnaval ou da Festa de Agosto. Americanos, canadenses, argentinos, venezuelanos, bolivianos, alemães, espanhóis, japoneses, coreanos e outros visitam a cidade com interesse no esoterismo e na natureza do lugar. Como turistas, esses visitantes vêm a essa remota cidade no sul de Minas Gerais com vontade de conhecer mais um lugar, distante e diferenciado (MacCannell 1999). Os motivos que levam turistas a viajar, segundo MacCannell (1999) são variados, mas têm relação com uma necessidade de compreender o mundo a sua volta. O turista move-se por diferentes estruturas totalizantes.

Fazer turismo consiste em ir e voltar modificado. Os sentimentos e atitudes são vislumbrados pela pessoa - admitindo-se que, na viagem, as pessoas são estimuladas por di- ferentes elementos e de forma distinta daquela experimentada no seu cotidiano - e o que era esperado pode ser, de forma imediata ou gradual, confrontado com o que foi vivido. Ou seja, a viagem leva a pessoa a provar suas expectativas e verificar os resultados. Analisando essas expectativas e resultados, o indivíduo verifica as modificaçóes pelas quais passou. A sensibilidade de cada indivíduo permite que, em diferentes graus, se consiga vivenciar diferentes situaçóes e se perceba diferentes aspectos da cultura local. De qualquer forma, os visitantes costumam gostar de suas visitas a São Tomé das Letras.

\section{Políticas públicas e sustentabilidade}

O patrimônio pode ser compreendido a partir de dois modos distintos: ao mesmo tempo em que é um empecilho, também pode ser considerado como um atrativo. É um empecilho porque não permite às mineradoras ampliar suas áreas de mineraçáo, apresenta dificuldades para as prefeituras realizarem obras de infra-estrutura e impóe restriçóes para certos setores como agricultura, pecuária, comércio e turismo. É um grande atrativo pelo valor histórico que possui e pela autenticidade que concede ao local. A indústria do turismo está sempre em busca do que pode ser considerado autêntico e passível de se tornar uma commodity. $\mathrm{O}$ turismo pode promover a valorização do patrimônio e criar uma demanda de preservação. Assim ocorre com centros históricos, como na cidade de Ouro Preto e em Tiradentes, também no estado de Minas Gerais.

A criação da necessidade de preservar e conservar esses patrimônios natural, arqueológico e histórico-arquitetônico depende da criação de consciência por parte da sociedade civil, empresários e governo em torno da preciosidade desses bens e de sua condição frágil. Também são 
necessárias medidas eficientes para a proteção desse acervo. A modernização, exemplificada por ruas asfaltadas, prédios novos, mineraçáo, comércio, indústria e agricultura extensiva, não são compatíveis com as necessidades de conservação do patrimônio histórico. Essa dicotomia entre o antigo e o novo cria conflitos de interesse e portanto é necessário uma ação combina$\mathrm{da}$, onde as iniciativas de preservação estão em consonância com as inovaçóes propostas pela sociedade que visam uma melhoria da qualidade de vida. A demanda pela preservaçáo do patrimônio e sua commoditizaçáo pela indústria do turismo vêm contribuindo para que prefeituras e empresários revisem suas políticas para facilitar o acesso de turistas a esse patrimônio.

Turismo e preservação ambiental ainda são palavras novas no vocabulário dos governos locais desses dois municípios. As prefeituras ainda estão em processo de adaptação para incorporar o turismo como uma nova atividade econômica geradora de empregos e tributos. A iniciativa continua sendo do setor privado, que oferece serviços nessa área. Entretanto, cabe ao poder público regular a atividade para que não haja degradaçáo do meio ambiente ou do patrimônio local. As assembléias legislativas têm se preocupado com a atividade.

Em São Tomé das Letras alguns vereadores vêm polarizando as discussóes para a questão da preservação do patrimônio local. Em Lagoa Santa existe uma preocupação do IEPHA/MG na preservação dos sítios arqueológicos, que é respaldada pela prefeitura. Como o município de Lagoa Santa faz parte de uma APA, há um acompanhamento mais ostensivo por parte de órgãos públicos estaduais e federais como o IEPHA/MG, IBAMA, FEAM e UFMG. O município de São Tomé das Letras, por não fazer parte de uma unidade de conservação tal como a APA, não se beneficia da legislação ambiental complexa e punitiva criada para a gerência de unidades de conservação. $\mathrm{O}$ poder público estadual e federal está presente, mas de forma menos ostensiva. Isso tem levado a uma atitude mais pró-ativa da sociedade civil, o grupo mais interessado no desenvolvimento de um programa de ecoturismo sustentável.

Em ambas as localidades, o turismo é visto como uma excelente alternativa de renda para a população local, frente a diminuição (ou até decadência) de outras atividades econômicas que estão estagnadas ou em declínio. $\mathrm{O}$ turismo vem sendo estimulado pelos governos estadual e federal e possui uma demanda continuada e crescente. As pessoas viajam cada vez mais e mais longe, querem conhecer os mais diferentes lugares, vivenciar novas experiências e trazer para casa provas de sua jornada. No caso de Lagoa Santa e de São Tomé das Letras, o turismo é amparado por atrativos de grande potencial, infra-estrutura básica amparada nos hotéis e pousadas, restaurantes e bares, mão-de-obra disponível e barata, e localização privilegiada por estarem próximas de duas metrópoles nacionais.

Atualmente, o Brasil possui uma legislação ambiental muito avançada e completa, que incorpora questóes pertinentes a todas as áreas de desenvolvimento econômico, propóe iniciativas interessantes de educação ambiental, prevê penalidades severas, entre outros. No entanto, a questão ambiental no Brasil ainda é tratada de forma marginal pelas diferentes instâncias governamentais e sua legislação, por enquanto em alguns casos, como os relatados aqui, ainda não soluciona todos os problemas existentes, ou não tem sua aplicação de modo eficaz. Todas as propostas de desenvolvimento de atividades econômicas como o ecoturismo ou turismo histórico-cultural, mesmo sendo consideradas pouco nocivas para o meio ambiente, se comparadas com atividades como a mineração ou agricultura, podem ter impactos diretos irreversíveis se não houver um plano de manejo e um monitoramento constante das atividades por órgãos fiscalizadores. 
Como afirma Honey (1999), estamos num momento de mudança de paradigmas, onde ecoturismo e conservação devem incluir benefícios e participação ativa da comunidade local e de agentes de desenvolvimento ecoturístico, conservação ambiental e proteção ao patrimônio. "Nature tourism has come to mean not just wilderness experiences but also activities that minimize visitor impact while benefiting both protected areas and the surrounding human population"14 (Honey 1999: 390). Esses novos paradigma e discurso são reflexos da necessidade de integrar elementos sociais, econômicos e ambientais quando do planejamento e implementação de atividades de ecoturismo. Uso de recursos naturais, manejo de áreas protegidas (no caso da APA - Carste de Lagoa Santa), e iniciativas de proteção ao patrimônio têm sido motivo de discussão entre governo, comunidades locais e setor privado por muito tempo. O que se faz necessário agora é uma ação combinada, visando a um desenvolvimento sustentado que inclua atividade industrial, ecoturismo e proteçáo ao patrimônio local.

Em suma, ao analisarmos atividades como o turismo e mineração e seus impactos sobre esses dois municípios, podemos refletir sobre alguns pontos importantes. O turismo tem surgido como principal alternativa às outras economias locais, como a agricultura e pecuária, hoje estagnadas; e representa um interesse maior do Estado de transformar as duas localidades em pólos turísticos locais com atrativos específicos e, conseqüentemente, vem causando importantes transformaçôes socioeconômicas e culturais nas duas localidades. $\mathrm{O}$ patrimônio histórico e

14. "Turismo de natureza representa não somente experiências do mundo selvagem, natural, mas também atividades que visem minimizar os impactos do visitante enquanto beneficiam tanto as áreas protegidas quanto as populações humanas vizinhas." (Tradução do Autor) natural tem sofrido fortes impactos com o aumento de visitantes, falta de manejo de áreas vulneráveis como cachoeiras, grutas, pinturas rupestres. Os novos visitantes contribuem diretamente para a manutenção dos conflitos sociais entre moradores locais. Lagoa Santa e São Tomé das Letras são dois exemplos paradigmáticos de municípios que vêm tentando se adaptar à nova legislação ambiental sem interromper suas atividades econômicas. A sustentabilidade dessas atividades depende diretamente de uma atividade conjunta entre sociedade civil, governo local e empresários na implementação de políticas públicas que estimulem o desenvolvimento de atividades que sejam econômica e ambientalmente sustentáveis.

\section{São Tomé das Letras and Lagoa San-} ta: mining, tourism, and threats to the historical and natural heritage.

abstract São Tomé das Letras thrives on mining, agriculture and tourism. Lagoa Santa thrives on mining, cement factories and agriculture. Mining is a threat to natural resources in both locations. These locations have distinct heritage landmarks. These heritage landmarks impose restrictions, crated to guarantee their preservation. Different local groups are in search for sustainable alternatives for the conservation of this heritage. The article makes a comparison of these two realities, trying to understand the sustainability of each mining town through the analysis of specific activities such as tourism, mining and the initiatives of preservation of cultural heritage. This article is based on ethnographic data focused on the social conflicts present in the two scenarios and the local public policies guided towards the development of sustainable economic activities for the environment and local heritage.

keywords Tourism. Environment. Heritage. Mining towns. Public policies. 


\section{Referências bibliográficas}

ANDRADE, Mário de. 1974. Aspectos da literatura brasileira. 5. ed. São Paulo: Martins Fontes.

APPADURAI, Arjun. 1996. Modernity at Large: cultural dimensions of globalization. Minneapolis: University of Minnesota Press, Public Works, v. 1.

BUTLER, Richard W. 2000. "Tourism and the Environment: a Geographical Perspective". Tourism Geographies 2(3):337-358

CANCLINI, Néstor García. 1994. "O Patrimônio cultural e a construção imaginária do nacional”. Revista do Patrimônio, IPHAN, 23: 95-115

ELIAS, Norbert. 2000. Os Estabelecidos e os Outsiders: sociologia das relaçóes de poder a partir de uma pequena comunidade, tradução de V. Ribeiro. Rio de Janeiro: Jorge Zahar Editores.

FLEISCHER, DAVID I. R. 2003. São Tomé das Letras: Uma etnografia de "ver para crer". Dissertação de Mestrado. Brasília: PPGAS-UnB,

FLEISCHER, DAVID I. R. 2000. Arqueologia em Lagoa Santa: tendão de Aquiles ou cabelo de Sansão. Dissertação de Graduação. Brasília: DAN-UnB,
HONEY, Martha. 1999. Ecotourism and Sustainable Development: who owns paradise? Washington: Island Press.

IBGE. 2000. Instituto Brasileiro de Geografia e Estatística (IBGE) http://www.ibge.gov.br/

MACCANNELL, Dean. 1999. The tourist: a new theory of the leisure class. Berkeley: University of California Press.

MEC/SPHAN. 1980. Proteção e Revitalização do Patrimônio Cultural no Brasil: uma trajetória. Brasília: SPHAN-PróMemória.

MEC/SPHAN. 1982. Bens Móveis e Imóveis Inscritos Nos Livros do Tombo do Patrimônio Histórico e Artístico Nacional. Brasília: SPHAN-PróMemória

ROJEK, Chris, e John URRY, (orgs.). 1997. Touring Cultures: Transformations of Travel and Theory. New York: Routledge.

SIMMEL, Georg. 1955. Conflict and The Web of Groups Affliations. Nova York: The Free Press.

SOUZA, Hélio Antonio de. 1997. Zoneamento Ambiental da APA - Carste de Lagoa Santa-MG. Belo Horizonte: IBAMA-CPRM.

STOCKING Jr., George. 1985. "Essays on museums and material culture”. In G. Stocking (org.), Objects and others; essays on museum and material culture. Madison: University of Wisconsin Press, pp. 3-14, série History of Anthropology, n. 3.

\section{autor David Ivan Rezende Fleischer}

Doutorando em Antropologia / State University of New York at Albany - E.U.A.

Recebido em 13/02/06

Aceito para publicação em 18/06/06 